\title{
Coronavirus Pandemic and Future Possibilities in Robotics Research
}

\author{
Dr. Saeed Niku*
}

\section{Department of Mechanical Engineering, California Polytechnic State University, California, USA}

With the Coronavirus pandemic, I have been thinking about the possibilities of using robots to help with the situation, and in what forms. The possibilities may include taking care of patients with humanoid-type robots and autonomous rovers to reduce the frontline healthcare personnel's exposure to the virus, use of robots in manufacturing to speed up the production of the needed products from masks to vaccines, the application of robots in checking individuals' temperature in public places, or preparing and delivering food at restaurants. The subject of autonomous delivery of food and packages by autonomous aerial devices is not new; it has been underway for some time anyway. These applications might be an extension or integration of shared concepts.

Obviously, this is not an exclusive list. And clearly, it will take some time before any one of these will bear fruit. However, it might be worth to start looking at new directions for applied robotics research in light of this pandemic as no one knows for how long it will continue to be an issue, or when once again something else like it might surface. Imagine that we develop the know-how to do any one of these things, and that the knowledge-base is readily available. At times when we do not have an emergency, we continue to use the robots for whatever task we want. They continue to make the frames of automobiles, they pick and place components and assemble parts, or paint a car. But when their service in these critical or emergency situations becomes crucial, robots can simply switch to new jobs with a change of a program. Their flexibility is a primary reason why we use robots; most robots are designed to perform tasks based on programs we develop, and can switch quickly and easily to do other tasks as long as we know how to do it; the re-tooling required to switch is much less than in dedicated manufacturing systems.

In recent attempts to retool many manufacturing plants, from automobiles to small plants, in order to produce ventilators and masks and such, the long delay was most probably due to the time needed to set up dedicated manufacturing systems to do something completely different. However, with robots at hand, even if their jigs and tools and other peripheral devices have to be changed, it is a much simpler and faster task to re-program them to perform other tasks. Saving time in itself is a huge issue in beating the culprit, in this case a virus.
And when a vaccine is developed and approved, the job of producing billions of vials of the vaccine will still be an issue. Although a dedicated system of vaccine production and packaging might be more efficient and faster, it might also take much longer to design and manufacture and install the system than using robots with an already-developed program at hand, until dedicated systems go online. With the negative effects of the shelter-at-home approach, shortening the time needed will have a tremendous positive effect on the future of the economy.

Autonomous devices such as mobile transport robots already can deliver parts to different locations on the factory floors, can deliver mail to offices, do routine tasks, and many more. They should also be able to deliver medicine to patients, deliver food and pick up the tray after use, handle stool samples and such, and many more, thus reducing the exposure of healthcare personnel. They could also participate in cleaning and disinfecting surfaces in public places, from hospitals and airports to subway stations and stores. We are only limited by our imagination.

One positive benefit of using robots for these tasks is also the psychological effects of a humanoid robot taking your temperature or disinfect the work area instead of workers who might also get exposed to the pathogens. A friendly robot in an airport, running around and taking temperatures, and saying thank you for being allowed to do so would be a great boost to humanizing robots, engineering, and the human-machine relationship.

No one is claiming that this will be done right away and we can enjoy the fruits of the research so soon, perhaps not for this pandemic at all. Many universities have shut down or are in online-instruction mode altogether, and doing research has almost completely stopped. Graduate students

*Corresponding author: Dr. Saeed Niku, Professor, Department of Mechanical Engineering, California Polytechnic State University, San Luis Obispo, California, USA

Accepted: September 24, 2020

Published online: September 26, 2020

Citation: Niku S (2020) Coronavirus Pandemic and Future Possibilities in Robotics Research. J Robotics Autom 4(1):166-167 
and researchers cannot access their labs, in some cases they are even forbidden from entering their labs due to fear of Coronavirus based on age or health issues, or students have left the university to live at home. This will certainly delay the research and development work. Yet, this should be a good lesson for us to learn, that we need to think of these possibilities and anticipate what may or will happen in the future and plan ahead.

When the restrictions are eased or lifted, I am sure we will find interested students who want to participate in this kind of research and development, perhaps a great oppor- tunity for our undergraduate researchers and more development-oriented laboratories and classes. So much research in universities revolves around development of the know-how for doing new and novel things. Examples include robotic insects, robot animals, drug-delivery microbots, and many. Perhaps this will be one additional area in which students work to develop the know-how. As mentioned earlier, the preceding list of possibilities is only a short and incomplete list. We may still not even know what we might need soon. Regardless, thinking and planning, and perhaps more importantly agreeing that this is something necessary to do, might help us significantly in the future.

DOI: $10.36959 / 673 / 367$ 